\title{
The Persistence of Stereotyped Dialect Features among Portuguese-American Immigrants from São Miguel, Azores
}

DAVID J. SILVA

\begin{abstract}
Among dialects of Portuguese, the variety indigenous to the island of São Miguel exhibits an inventory of vocalic features not found elsewhere in the Lusophone world. The most emblematic characteristics of this dialect are the front round vowels $[y]$ and $[\phi]$, which correspond to $[u]$ and [ou/oi] (respectively) of the European standard language. There are also systematic differences in the pronunciation of the tonic vowels, reflexes of a historical chain shift: sete 'seven' is often rendered in S. Miguel as [sæt] (Std. [sct]), avó 'grandmother' as [ $\left.e^{\prime} v o\right]$ (Std. [ $\left.e^{\prime} v J\right]$ ), and avô 'grandfather' as [ $\left.e^{\prime} v u\right]$ (Std. [ $\left.\left.e^{\prime} v o\right]\right)$. While these characteristic are attested in the contemporary speech of the island, one might ask whether they persist in the speech of Azorean emigrants in the United States. This paper presents a phonetic analysis of four emigrants from the village of Nordeste, members of the same family, each of whom presents different phonetic behaviors. While three speakers preserve most of the speech reflexes characteristic of the island, one presents a vocalic inventory more like that of the standard language. This variability reflects a tension between behaviors emblematic of Micaelense identity (e.g., $[y]<[u])$ and a need to accommodate to sociolinguistic pressures exerted by the standard language, which predominates in the larger community of Portuguese immigrants.
\end{abstract}

\section{Introduction}

Among the dialects of Portuguese spoken worldwide today, the variety spoken on the Azorean island of São Miguel (St. Michael) exhibits a vowel inventory unique to the Lusophone world. The most emblematic characteristic of this dialect is, without doubt, the use of the stressed front rounded vowels [y] and $[\varnothing]$, corresponding to standard Portuguese [u] and [ou/oi], respectively, as in (1). The Micaelense vowel [ø] likewise appears in the context of [o] followed by the palatal fricative [3]. 
(1) [y] (orthographic $u$ )

[ø] (orthographic oi, ou, o followed by $j$ )

\begin{tabular}{|c|c|c|c|c|c|}
\hline ['yve] & $u v a$ & 'grape' & {$[\varnothing t]$} & oito & $\begin{array}{l}\text { 'eight'" } \\
\text { 'night' }\end{array}$ \\
\hline ['fryte] & fruta & ‘fruit' & [nøt] & noite & 'night' \\
\hline [kryf] & cruz & 'cross' & [pøk] & роисо & 'little, few' \\
\hline [e'zyl] & azul & ‘blue’ & [ø3] & hoje & ‘today’ \\
\hline
\end{tabular}

There are also systematic differences in the pronunciation of the other tonic vowels (save/i/). For example, dedo 'finger' is pronounced by many Micaelenses as ['d $\varepsilon \mathrm{d}(\mathrm{u})]$ ( Standard Portuguese ['dedu]), perna 'leg' as ['pærne] ( Std. ['perne]), etc.

(2) Vowel Correspondence Standard Standard $\sim$ S. Miguel

Std [i] SM [i]

Std $[\mathrm{ej}] \sim \mathrm{SM}[\mathrm{e}]$

Form

Micaelense

Orthographic

Variant(s)

Form / Gloss

Std $[\mathrm{e}] \sim \mathrm{SM}[\varepsilon]$

['ditu]

[dit]

Std $[\varepsilon] \sim$ SM $[æ]$

['lejti] ['lejti] [le:t]

dito 'said'

Std $[\mathrm{a}] \sim \mathrm{SM}[\mathrm{a} / \mathrm{p} / \mathrm{\jmath}$

['dedu] [d $\varepsilon d]$

leite 'milk'

['perne]

['pærne]

dedo 'finger'

Std [0] SM [o]

['patu]

[pat] [p

perna 'leg'

Std [o] SM [u]

[e'vo]

[e'vo]

[e'vo]

[e'vu]

Std [u] SM [y]

['tudu]

[tyd]

avó 'grandmother'

$a v \hat{o}$ 'grandfather'

tudo 'everything'

These characteristics have been well attested in the speech of the island, in the $19^{\text {th }}$ century (Leite de Vasconcellos, 1890-92; Gonçalves Vianna, 1887$-89), 20^{\text {th }}$ century (Rogers, 1940, 1948; Silva, 1986, 2005; Blayer, 1992) and more recently (Rolão Bernardo and Montenegro, 2003). Without a doubt, the most detailed phonetic account of the Micaelense dialect is that of Rolão Bernardo (i.e., Part I of her 2003 collaboration with Montenegro), in which one finds meticulous acoustic description, location by location, across the island. $^{2}$

Working from the correspondences presented in (2), Rogers was the first to note that the differences between the Micaelense dialect and the standard language could be captured in terms of a chain shift (an observation made more widely known by Martinet in his 1952 classic "Function, Structure and

\footnotetext{
${ }^{1}$ The deletion of unstressed final non-low vowels is common in all varieties of European Portuguese (Mateus 1982; Silva 1997, 1998).

${ }^{2}$ Most (if not all) of the non-standard vowel realizations discussed herein are not specific to São Miguel. As has been well documented, for example, front rounded $[y]$ and $[\varnothing]$ can be heard sporadically on several other Azorean islands (Blayer 1992); shifted variants of the stressed back vowels have also been attested among speakers from the Algarve and the Alentejo (Blayer 1992, Dias 2000, and sources cited therein); and the monophthongization of [ow] and [ej] can be heard in a number of southern continental dialects (Cintra 1983). What makes São Miguel Portuguese unique is the particular combination (and seemingly large number) of non-standard variants that make up the variety's vowel inventory.
} 
Sound Change"), one whereby each stressed vowel is displaced one region in a counterclockwise fashion. ${ }^{3}$

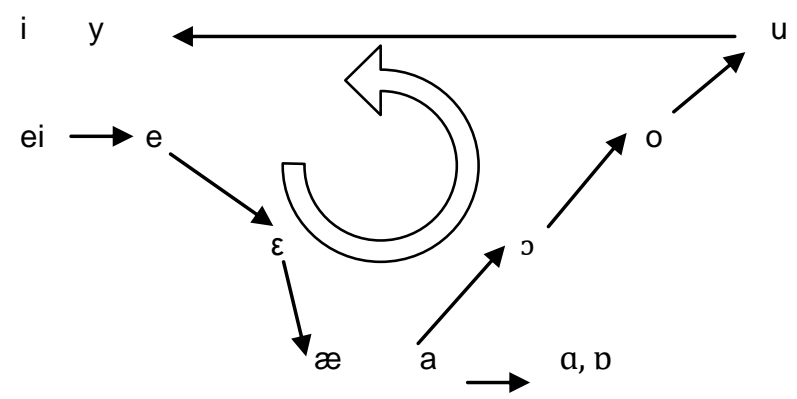

Figure 1: The Portuguese Vowel Shift (viz. Rogers 1940, 1948; Martinet 1952)

The results of this chain shift, alongside various processes of monophthongization - eu > [e] 'I', pai > [pa:] 'father', chapéu > [je'pe:] 'hat', foi $>$ [fø] 's/he was', and couve $>$ [køv] 'collard' - gives the pronunciation of the island its unique profile in the Lusophone world. One must note, however, that of these characteristics, there are those most emblematic of the Micaelense dialect. At the end of her work, Rolão Bernardo writes the following: “... a frequência e a sistematização de emprego das vogais [ü], [ö] e até mesmo [a], ainda que esta última seja evitada nos meios citadinos, não encontram paralelo no universo da Lusofonia, constituindo marcas indeléveis de um modo de falar muito típico da ilha de São Miguel" (2003:115).

While these phonetic features are well attested in the contemporary speech of São Miguel, one might wonder if they persist in the pronunciation of those Micaelenses who have emigrated, be it to the United States, Canada, Brazil, or elsewhere. This question is worthy of attention in the U.S. context, especially when one considers the sociolinguistic forces - and outright prejudice - that many Micaelenses encounter within the Luso-American community. Given that the majority of U.S. Portuguese immigrants control a speech variety more attuned to the norms of the standard language including (but not limited to) the system of stressed vowels, immigrants from São Miguel find themselves a minority within the minority. As we shall see, under such pressure, some Micaelenses opt to abandon certain typical features of their native dialect, adopting a pronunciation akin to that of the standard. Other Micaelenses, however, preserve a few key typical (or better, stereotypical) features of the dialect $-[y]$ and $[\varnothing]-$ but they do not manifest all of the results arising from

\footnotetext{
${ }^{3}$ Silva (1986) suggests that this pattern is better conceptualized not as single circular shift, but rather, as two interrelated shifts, a downward movement of the front vowels and a opposing upward movement of the back vowels.
} 
the chain shift presented in Figure 1. Finally, some speakers, particularly the minority of whom whose social network does not extend far beyond the sub-community of Micaelenses in the United States, preserve a majority of the dialect's acoustic characteristics, manifesting a system that is traditional, conservative, stereotyped, and stigmatized.

\section{An Acoustic Analysis of Accented Oral Vowels in Portuguese}

\subsection{Accented Oral Vowels in the Standard Language}

Before considering the vowel patterns presented by speakers of the São Miguel dialect (both those resident on the island and those who have immigrated to the United States), let us briefly review the basic features of the vowel system found in standard European Portuguese. It is widely known that the standard variety presents seven accentuated oral vowels: [i e $\varepsilon$ a $\supset$ o u $]$. Martins (1988) informs us that each of these vowels occupies a distinct region in acoustic space: the frequency values for the first and second formants do not manifest any overlap. In Figure 2, each marker represents the average values for F1 in Hertz along the Y-axis (a reflex of vowel height) and F2-F1 along the $\mathrm{X}$-axis (a reflex of vowel backness).

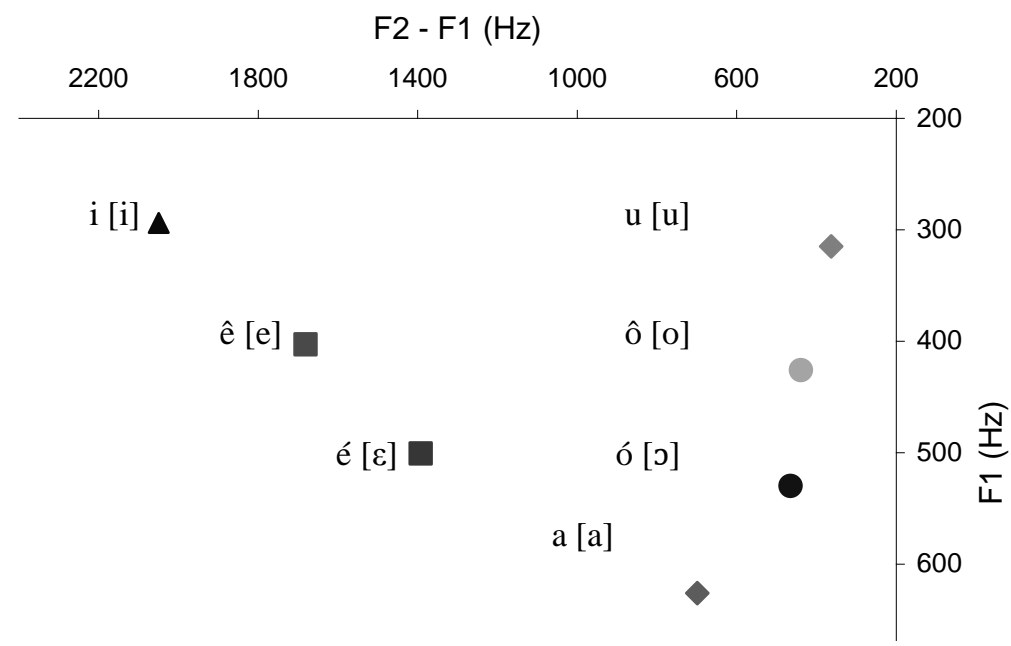

Figure 2: Accented vowels of standard Portuguese, composited from the data of nine speakers (based on data in Martins 1988)

From a typological perspective, this vocalic system is unmarked: like the plurality of languages found in the world today (Ladefoged and Maddieson, 1996; Crystal, 1997), standard Portuguese presents seven oral vowel phonemes, arrayed in a symmetrical, parallel system. 


\subsection{Accented Oral Vowels in the Micaelense Dialect}

Impressionistic and instrumental accounts of the São Miguel dialect make clear that this variety of the language presents a vowel system considerably different from that of the standard. For example, Silva (2005) illustrates the relative positions of the oral accented vowels in the speaker of a female speaker of the Micaelense dialect, Senhora T, a native of the village of Nordeste. In Figure 3, the larger markers represent T's average values for F1 and F2-F1 (in Hz); the smaller markers represent the vowel positions of the standard language, as reproduced from Figure 2. The arrows emphasize the different locations for each vowel in the correspondence, partially reproducing the vowel shift arrayed in Figure 1.

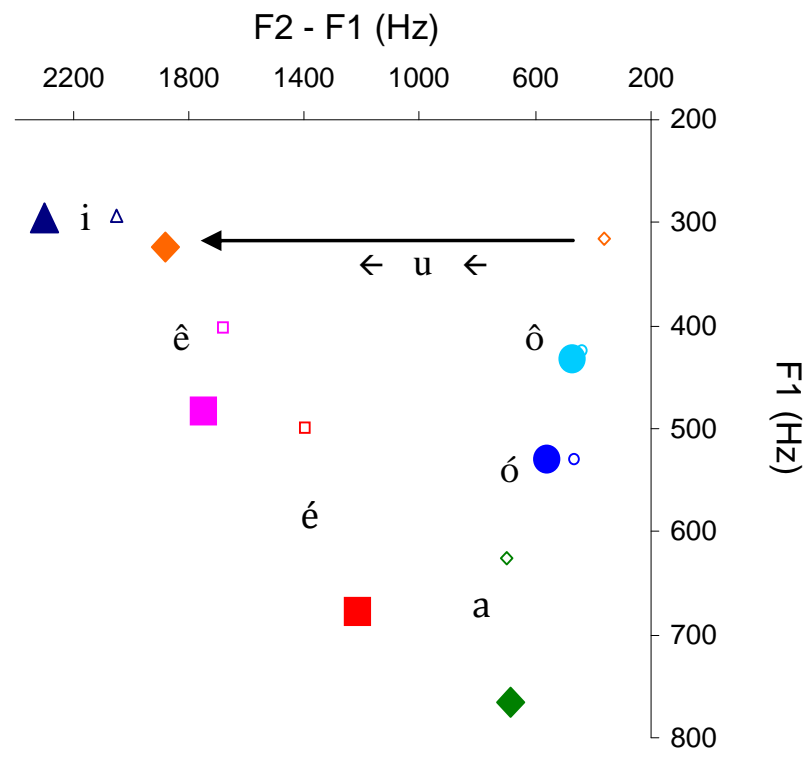

Figure 3: The Vowel Space of Sra. T, native and resident of Nordeste, S. Miguel (as reported in Silva 2005)

In the output of this speaker, the front vowels are lower than their standard language counterparts $(\hat{e}>[\varepsilon]$ e $e ́ p[æ])$; there is also lowering of the central low vowel $a$, with no observed backing or rounding. The mid back vowels, $o$ and $\hat{o}$, are situated in approximately the same position as they are found in the standard language; there is no appearance of there having been a shift, and their relative positions are distinct. The high front vowel, $i$, is a bit advanced (with no change in height). The high back vowel, $u$, is quite far removed from 
its standard counterpart, appearing in the high front region of the vowel space; moreover, its percept is that of a clearly rounded vowel, namely [y].

In the vowel space of another resident of Nordeste, Senhor F (Figure 4), we encounter even more convincing evidence of the Portuguese Vowel Shift, as indicated by the arrows. As was the case for T, F's vowel space presents downward movement of the front mid vowels as well as fronting of the back high vowel. In this space, however, we find clear (albeit small) upward movements of the mid back vowels (as predicted by Figure 1), as well as some backing of the low vowel.

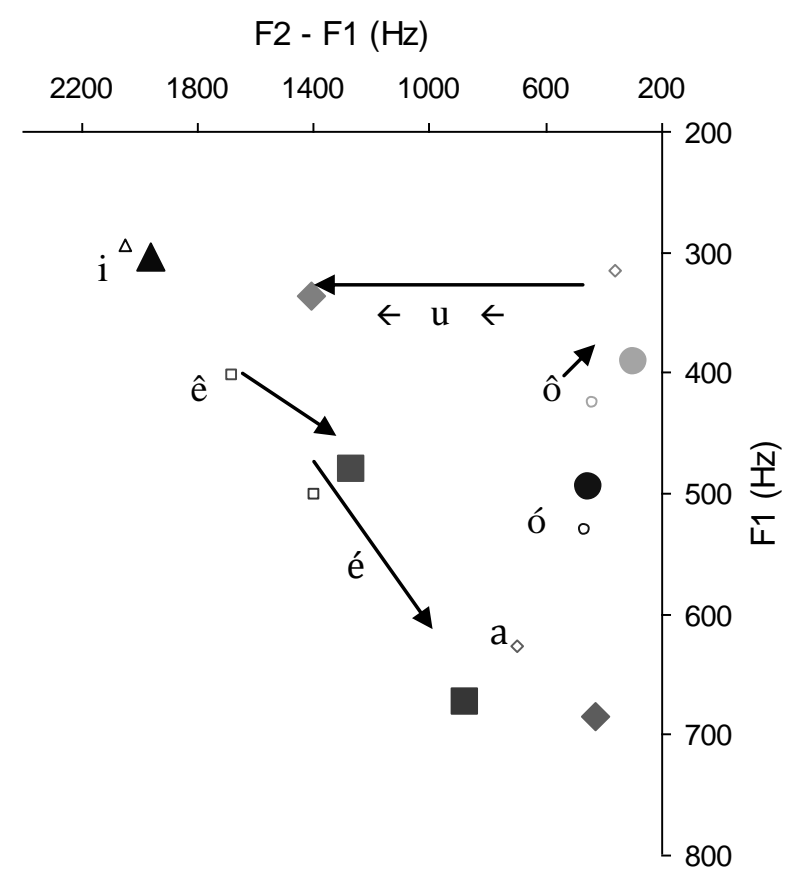

Figure 4: The vowel space of Sr. F, native and resident of Nordeste (as reported in Silva 2005)

The vowel spaces of these two speakers from Nordeste do not conform completely to the situation presented by Rogers - i.e., a counterclockwise movement of stressed oral vowels, with unambiguous displacement of each vowel into a new space. All the same, each speaker manifests at least some degree of vowel displacement, particularly as regards the fronting of $[u]$ to $[y]$ and the downward shift of the front vowels. Such variability is attested in subsequent research. As Silva notes (2005:6), for example, stylistic factors influence the degree to which speakers manifest the full effects of Rogers's vowel shift; more specifically, he notes that speakers tend to "undo" the effects of the shift in more formal speech styles. Moreover, as Rolão Bernardo 
writes, "Colheram-se interessantes registos que dão testemunho da consciência, que os locutores demonstram ter, da existência de variação no português falado na ilha" (2003:113). In brief, phonetic variability is normal, be it a matter of speech style, geography (even in a local as small as São Miguel, which is only $750 \mathrm{~km}^{2}$ with some 140,000 inhabitants), or language attitudes (especially toward such a stigmatized variety). That said, such variation whatever its source - should not obscure the presence of the emblematic characteristics of the dialect, which are carried to North America by Micaelense émigrés.

\subsection{The Micaelense Vowels System in the United States: Four Speakers}

When Micaelenses leave their homeland, to what extent are their local speech patterns preserved? Do they maintain the vowel system characteristic of the island or do they adopt other pronunciations? As we shall see, the results vary according to each speaker, but with generalizations worthy of note.

In this paper, we consider the oral productions of four speakers of the Micaelense dialect, each with somewhat different sociolinguistic profiles, but all belonging to the same family: a mother and three of her adult sons. The mother, "MB", was approximately 70 years of age at the time of recording; born in the United States, she returned to São Miguel as an infant and was raised in Nordeste. She ultimately married another native speaker of the dialect (from the town of Ribeira Grande), and gave birth to three sons in São Miguel between 1943 and 1947. In 1949, the family emigrated to the United States and lived in the Portuguese community in and around Cambridge, Massachusetts. In 1956, a fourth son was born. The three sons interviewed for this study are the eldest ("L"), the second ("J") and the youngest ("S"). It bears explicit mention that while the mother is fully literate in Portuguese, none of her children present literacy skills in the language; for them, linguistic behaviors in Portuguese are limited to the aural-oral modality.

The materials that serve as the base of this project were collected during the summer of 1997, in the cities and towns surrounding Boston, Massachusetts, home to a once-vibrant community of Azorean immigrants. Each subject was asked as series of basic demographic questions (age, education, employment, etc.), as well as a series of questions focusing on their relative use of Portuguese vs. English. For example, subjects were asked to characterize whether they used "only Portuguese," "mostly Portuguese," "both English and Portuguese," etc. when they engaged in a variety of tasks: chatting with a spouse, a sibling, an older family member, or a younger family member; dreaming; praying; adding numbers; etc. ${ }^{4}$ Participants were then presented with a series of photographs of common objects - a radio, a pair of scissors, articles of clothing, fruits and vegetables, etc. - and simply asked to identify each. (A list of the items pictured on the cards appears in the

\footnotetext{
${ }^{4}$ In many cases, the data gathered from these questionnaires has been supplemented by observation by the author, both with and without participation.
} 
appendix.) As presented to each subject, the goal of the study was to discern how much Portuguese vocabulary they had retained, thereby encouraging them to attend to the lexemes as they related primarily to meaning (and not form). Doing so was intended to optimize the authenticity of each participant's speech, despite the controlled, non-conversational nature of the task.

The interviews were recorded on a standard audiocassette using a Marantz recorder and an Audio Technica cardioid microphone. The audio signals were subsequently converted to digital .wav format at a sampling rate of $22 \mathrm{~K}, 16$ bits for acoustic analysis using the Praat software developed by Boersma and Weenink.

For each vowel, the values of the first and second formants were determined by identifying the segment's durational midpoint, selecting approximately five vowel pulses on either side of this point (so as to minimize any effects of adjacent consonants), and querying the software for the averaged F1 and F2 values for this selected central region (Figure 5).

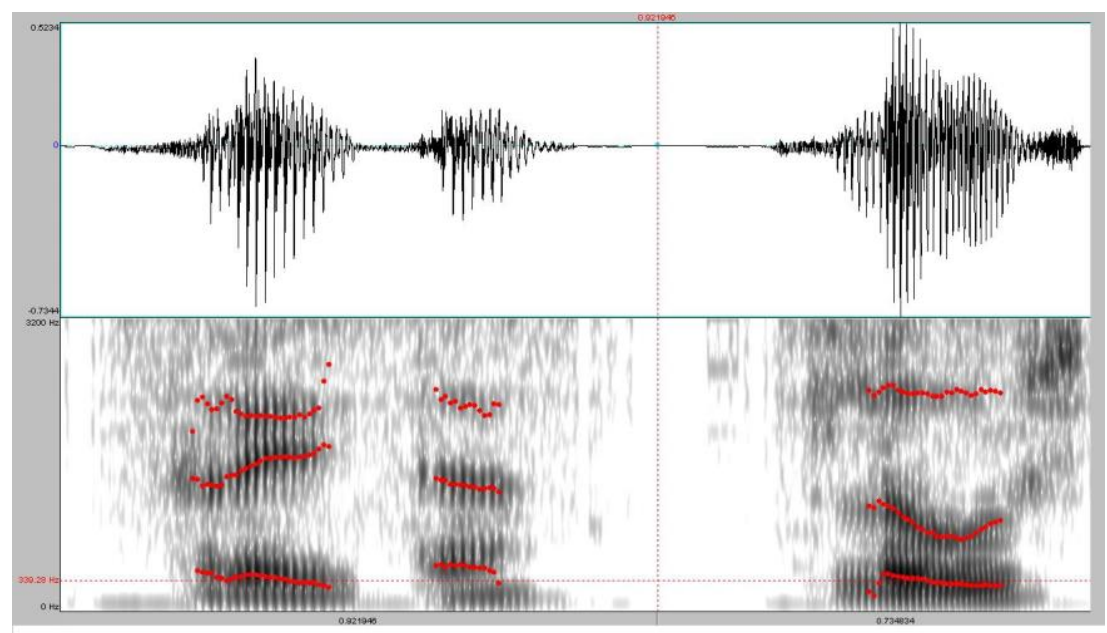

Figure 5: Spectrogram of fruta 'fruit' (left) and flores 'flowers' (right) as produced by Speaker S. Note the wide spacing of the first and second formants in fruta, indicative of a high front vowel. Note, too, the similarity of F1 in the stressed vowels in both word (approximately $340 \mathrm{~Hz}$ ), suggesting a high tongue position.

2.3.1. The Vowel Space of Speaker MB (female, 70 year old). The vowel space of the mother, MB, appears in Figure 6. Here one observes many characteristics typical of the island, in a vowel space strikingly similar to that of Nordeste resident T: the fronting of the high back vowel $u$ (from [u] to [y]), the realization of the mid back vowel diphthongs oi and ou as the mid front vowel $[\varnothing]$, a downward chain shift of the front vowels, and a lowering of the 
central vowel $a$ (without significant backing). The mid back vowels $o$ and $\hat{o}$ remain essentially in the same region as they might in the standard language.

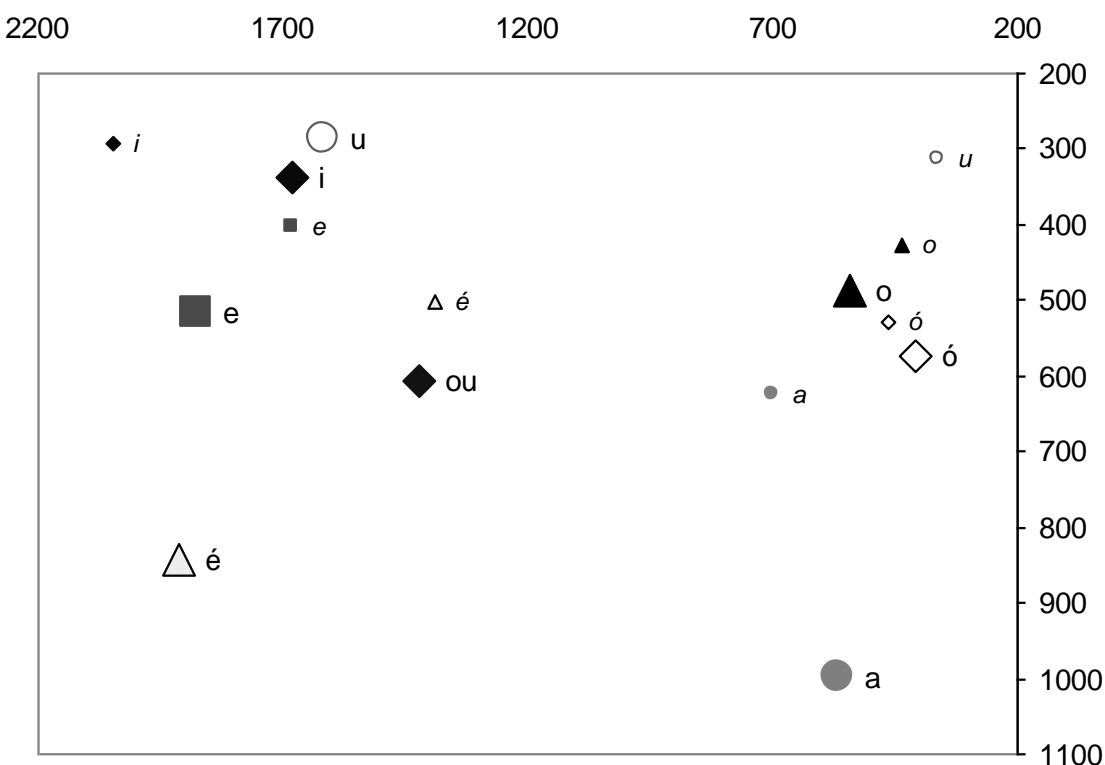

Figure 6: The Vowel Space of Speaker MB.

In this and subsequent displays, the $\mathrm{X}$-axis corresponds to $\mathrm{F} 2-\mathrm{F} 1$ (in $\mathrm{Hz}$ ) and the $\mathrm{Y}$ -axis to F1 (Hz). Moreover, the smaller markers serve as reference points, representing the F1 and F2-F1 values of the standard language (from Martins 1988)

2.3.2. The Vowel Space of Speaker L (eldest son, $\sim 55$ years). The vowel space of speaker L (Figure 7) differs from that of his mother in several respects. While we observe downward movement of the front mid vowels $\hat{e}$ and $\dot{e}$, there is no significant movement of the low vowel $a$. We also see that the orthographic diphthongs $o i$ and $o u$ are represented by a mid central rounded monophthong (approximating IPA [e]), as opposed to the more clearly fronted $[\varnothing]$ of MB's system. In addition, the two mid back vowel phonemes $\hat{o}$ and $o$ occupy essentially the same acoustic space, representing the effects of an apparent vowel merger. Finally, and perhaps most notably, the vowel $u$ remains in a position corresponding to that one would expect in the standard language, in the high back corner of the space: L does not present [y], perhaps the dialect's most emblematic feature. 


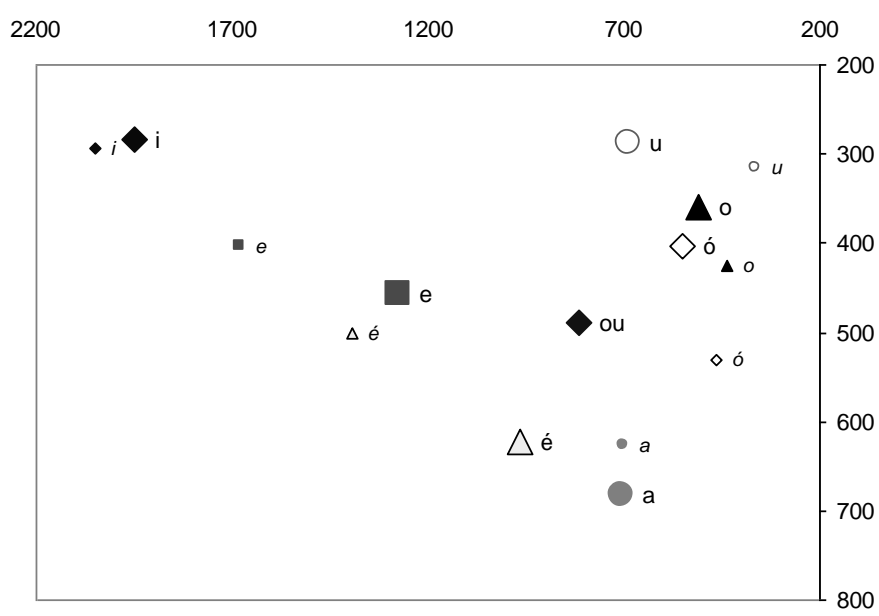

Figure 7: The Vowel Space of Speaker L.

Note the lack of a front rounded vowel and the (near) merger of the back mid vowels.

2.3.3. The Vowel Space of Speaker $\mathbf{J}$ (second son, $\sim 53$ years). The vowels space of speaker $\mathrm{J}$ is yet again different from those presented by MB and L. In Figure 8, we observe varying degrees of downward motion of the front vowels (including $i$, which is rather unexpected), including a remarkably large displacement of mid open é. The low central vowel is backed, lowered and quite rounded (a feature not readily presented two-dimensionally). The mid back vowels sit in regions approximating those of the standard language, while the ou/oi diphthongs correspond to a mid rounded monophthong, and the high back vowel is fronted to [y], as might be anticipated.

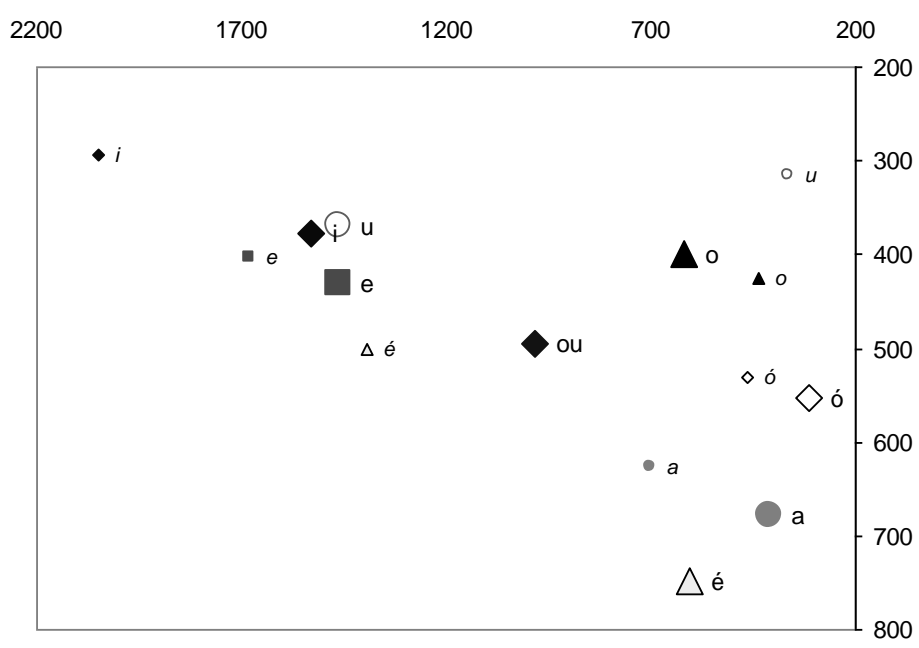

Figure 8: Vowel Space of Speaker J. 
2.3.4. The Vowel Space of Speaker $S$ (youngest son, $\sim 42$ years). The vowel system of speaker S (Figure 9) merits special attention in that it best represents the vowel inventory most typically (or stereotypically) associated with the São Miguel - despite the fact that speaker S was born in the United States and has never once visited the island. While the mid front close vowel $\hat{e}$ has not been lowered, it has been backed. With this exception noted, the remaining vowels occupy the positions that we might expect per item (3): $e$ is lowered; $a$ is lowered, backed, and often rounded; $o$ and $\hat{o}$ are raised to the positions of $\hat{o}$ and $u$, respectively; and $u$ manifests itself as high front rounded [y]. The diphthong oi/ou is a front-central rounded monophthong.

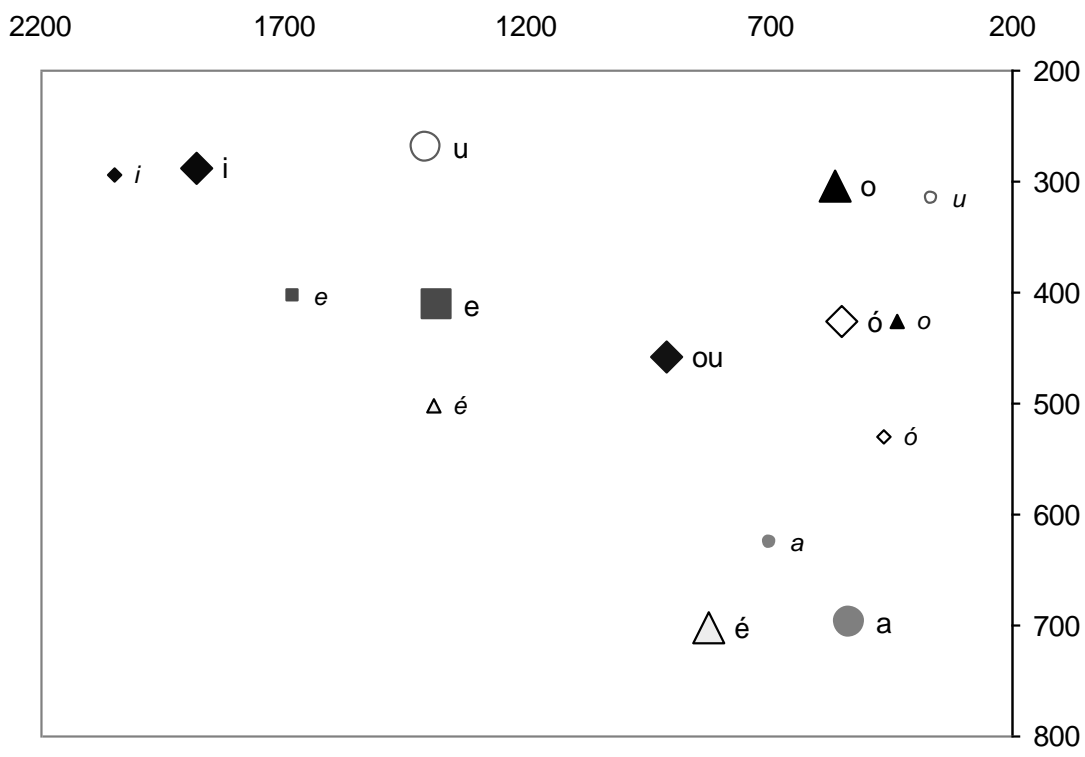

Figure 9: The Vowel Space of Speaker S.

\section{Analysis}

As documented in $\S 2.3$, each of our four speakers preserves at least some of the phonetic patterns typical of the island, but to varying degrees. It can be argued, for example, that $\mathrm{L}$ manifests the system least clearly associated with that of the island, without completely aligning with the standard language: as compared to the standard, L's mid front vowels have been lowered, manifesting a reflex of the front (lowering) chain shift. Also unanticipated is 
the approximation of the two back vowels toward a single overlapping region. Missing in L's speech are clearly front rounded vowels. On the other hand, the vowel space of the youngest speaker, $\mathrm{S}$, is the most typical of the island, with both the front and back chain shifts clearly in evidence. Between these two cases are the vowel systems of MB and J: their phonetic output represents an accommodation of the insular system (with its front rounded vowels) to a very standard-like system, i.e., that which predominates in the Luso-American speech community.

Having considered the vowels spaces presented by each of these four Micaelenses, how might we explain the observed differences, particularly in light of their shared familial connections? Critical to the analysis is a fuller understanding of each speaker's sociolinguistic profile, particularly with respect to their relative positioning vis-à-vis the larger Lusophone community. Of central importance in this respect is an appreciation for the low social standing accorded the São Miguel dialect by other speakers of European Portuguese. Simply put, Micaelense speech is highly stigmatized. This marginal status presents itself both in terms of how other Portuguese speakers sometimes describe the Micaelenses (e.g., as "os japoneses," a reference to their purportedly unintelligible dialect) and how the Micaelenses often speak negatively of their own speech. (Indeed, in the process of my fieldwork, participants often questioned why we wanted to capture their particular speech, particularly given that their Portuguese was so "bad.") Such negative attitudes, however, are abated to a great extent on São Miguel itself, specifically in the presence of the social networking forces that support the regular use - and social capital - of the local dialect (Milroy, 1987, among others). While Micaelense of higher socioeconomic status will often comment negatively upon the linguistic behaviors of their insular compatriots, the discussion is most often one of relative use: the Micaelense dialect is readily heard across the island by speakers of all social levels, particularly in the most casual of social contexts.

When a Micaelense leaves the island, however, the sociolinguistic context shifts dramatically. In the North American immigrant context, the Micaelenses find themselves living side by side with Lusophones from other European Portuguese speech communities, each associated with speech varieties unequivocally more aligned with the lingua padrão. As such, the Micaelenses encounter new pressures to modify their speech behaviors in the direction of the standard variety.

Consider the more detailed social realities of speaker L. At the time of the recording, he functioned primarily within the culturally dominant Anglophone community, yet still maintained linkages to the Azorean community. The dominant Portuguese sociolinguistic force in his life is, without a doubt, his wife and her family, natives of the island of Faial. Immediately upon marrying, L and his wife secured an apartment directly below that of his in-laws, thereby providing for over five years of daily interaction with speakers 
of the most standard-like dialect of Azorean Portuguese (Rogers, 1940; Silva, 1986; Blayer, 1992). Years later, after $\mathrm{L}$ and his family had moved to a single-family home, L's mother-in-law came to live with his family, once again providing daily exposure to and interaction with the Faialense dialect, a context that persisted for over 10 years. In other words, from his early 20's onward, L entered into a high density relationship with non-Micaelense speakers in the Lusophone context: his interactions with speakers of this more normative variety of Portuguese were frequent and significant. Under these circumstances, one can reasonably hypothesize that $\mathrm{L}$ would have encountered pressure to modify his phonetic patterns, an hypothesis supported by his very standard-looking vowel inventory.

At the other extreme of the sociolinguistic spectrum we encounter speaker $\mathrm{S}$, who controls a very stereotypical version of the Micaelense dialect. Though $\mathrm{S}$ spoke the Micaelense dialect as his first language, as an adult, he lacks significant connections with the larger Lusophone community. Indeed, S is almost completely integrated into the dominant English-speaking culture. Hence we find that $\mathrm{S}$ had entered into a very low density relationship with the Lusophone community: interactions with Portuguese speakers are limited to family members of older generations - parents, grandparents, and aunts and uncles - all native speakers of the Micaelense dialect. With his siblings and cousins, S has habitually communicated only in English. Moreover, S's use of Portuguese as an adult is rare; he self-reports that all of his habitual cognitive functioning (dreaming, counting, etc.) occurs in English. The only person with whom he occasionally uses Portuguese is his mother and even in this, he is prone to produce English more often than Portuguese. Without regular frequent and significant social interactions with speakers of Portuguese (from any dialect), $\mathrm{S}$ has not received the input sufficient for establishing either the linguistic competence or the attendant attitudes of the broader Lusophone community. He remains a sociolinguistic island, limited in his awareness of Portuguese beyond that of São Miguel.

In contrast, speakers $\mathrm{MB}$ and her second son, J, have personal histories that include social connections with the Lusophone community. While both MB and $J$ have had direct contact with speakers of other dialects of Portuguese, their primary social networks in the Luso-American context points to medium-to-high density interactions with other Micaelenses. It should be noted, however, that in both cases, these linkages were much stronger during the 1950s and 1960s than they were at the time of the data collection; for MB, links to the Portuguese community are still present, while for J, these social connections have all but evaporated. Regardless of these differences, MB and J present social networking profiles intermediate to those of $\mathrm{L}$ and $\mathrm{S}$. As such, it is altogether unsurprising that their pronunciation manifests some degree of compromise in the direction of the standard language, but without setting aside the dialect's primary sociolinguistic indicators: linguistic reflexes that are distinct from the standard but do not 
appear to be sensitive to stylistic variation (Labov, 1972; Bell, 1983), primarily [y], [ø], and a sharply lowered é manifesting as [æ]. Without the same degree of frequent, significant contact with a more standard(-like) dialect, as is the case for $\mathrm{L}, \mathrm{MB}$ and $\mathrm{J}$ have less pressure to abandon these phonetic indicators; at the same time, their speech output suggests some degree of awareness regarding the social norms of the larger Lusophone community.

\section{Conclusion}

Although many of the acoustic vocalic properties of the São Miguel dialect persist in the Lusophone community of Greater Boston, we find that even among members of the same nuclear family, there are observable differences in terms of how the stressed oral vowels of each speaker pattern. Contrary to what might have been expected, however, it was not the oldest member of the family who presented the most conservative dialect-based speech patterns: rather, it was the youngest son, who - curiously enough - is the only member of the family to never have passed any time at all on the island. In an attempt to explain this fact, we appeal to the notion of social networking: the speaker with the fewest ties to the larger Lusophone community is he who has preserved the majority of speech behaviors characteristic of the São Miguel sub-community. On the contrary, the speaker with the most frequent and intimate ties to native speakers of more standard varieties of European Portuguese manifests a vowel space that more clearly corresponds to the standard language. In this interpersonal variability we witness a tension between verbal behaviors that mark a speaker as Micaelense (such as [y] in place of $[u]$ ) and those which represent a response to the social and linguistic forces of the standard.

What more, then, might be offered regarding the relationship between cultural identity and corresponding language behaviors? Here we might appeal to a modified version of Berry's (2003) model of acculturation, which juxtaposes an individual's desires to value / maintain his local cultural identity with his desire to participate in the larger community, thereby extending himself beyond his native cultural context. ${ }^{5}$ As a first pass, let us consider the cross-tabulation of American vs. Portuguese identity, as arrayed in Figure 10.

\footnotetext{
${ }^{5}$ Thanks to Verlieann Malina-Wright of the Kula Kaiapuni O Anuenue for making us aware of Berry's model through her own work in Hawai'ian language and culture educational initiatives.
} 


\begin{tabular}{|c|c|c|c|}
\hline & & \multicolumn{2}{|c|}{ Maintenance of Portuguese Language and Culture } \\
\hline & High & $\begin{array}{c}\text { Integrated / Bicultural } \\
\text { (Bilingual) }\end{array}$ & $\begin{array}{c}\text { Assimilated } \\
\text { (English Dominant) }\end{array}$ \\
\cline { 2 - 4 } $\begin{array}{c}\text { Contact- } \\
\text { Participation } \\
\begin{array}{c}\text { with } \\
\text { Anglophone } \\
\text { Community }\end{array}\end{array}$ & Low & $\begin{array}{c}\text { Traditionalist / } \\
\text { Segregationist } \\
\text { (Portuguese Dominant) }\end{array}$ & $\begin{array}{c}\text { Marginalized } \\
\text { (?) }\end{array}$ \\
\hline
\end{tabular}

Figure 10: Matrix of Lusophone Maintenance vs. Contact-Participation with the Dominant Anglophone Community (after Berry 2003).

Based on the interviews and ethnographic observations of the four subjects, it seems most apt to assign the mother, MB, to the category "Traditionalist" (e.g., high Portuguese identity but Low American Contact-Participation), while her sons would line up (by age) along the segment formed by "Integrated" to "Assimilated," with L, the eldest, being the most integrated and S, the youngest, being the most clearly assimilated. Such an assessment aligns well with readily-observed patterns of language use in the Luso-American community. Traditionalists (such as MB) are clearly Portuguese-dominant, but often control limited Second-Language English. Those in the integrated box tend to be bilingual (more often than not English-dominant, just as $\mathrm{L}$ and $\mathrm{J}$ ), while those in the assimilated box tend to use Portuguese the least frequently, and present idiosyncratic gaps in their ability to access vocabulary (very much the case of S). Where the model in Figure 10 falls short, however, is in accounting for the observed patterning in the vowel systems of the four speakers, as discussed in $\S 2.3$. The problem would be that the model lacks specific reference to Micaelense identity, as opposed to a more generalized "Portuguese" identity.

In addressing this matter, it is worth considering more carefully the case of the youngest speaker, $\mathrm{S}$. What is perhaps most striking about S's situation is apparent mismatch between his linguistic behaviors and his cultural identity. While fully aware of his Azorean heritage, $\mathrm{S}$ is a U.S. citizen by birth and claims a fully authentic American ethnic identity. To paraphrase Marsella and Kameoka (1989), S's ethnic identity as an English-speaking American refers to the extent to which he "endorses and practices a way of life associated" with the dominant culture. Indeed, S's English language speech patterns clearly mirror the norms of the Boston area, complete with the loss of post-vocalic [r] and use of backed [a] for lexemes such as "aunt" and "bathroom." When put into a position to function in Portuguese, however, $\mathrm{S}$ has no choice but to reference a very limited sense of Portuguese ethnic identity: that 
associated with his family. In this regard, $\mathrm{S}$ is not so much ethnically "Portuguese" as he is "Micaelense," independent of "Portuguese."

In light of these considerations, let us pursue a second model, in which Portuguese identity is arrayed against local (Micaelense) identity. In Figure 11 , we find a more clearly discernable connection between identity and speech behaviors among our four speakers. For MB, J, and S, each of whom might arguably bear a more undiminished sense of Micaelense identity (as compared to L), we observe speech that vacillates between a more stereotyped version of the dialect (speaker S) and what is labeled in the figure as "Accommodated Micaelense" (speakers MB and J), or what Rogers might refer to as "Luso-São-Miguelian":

Luso-São-Miguelian is standard Portuguese superimposed on São-Miguelian, with the resultant interplay. However, as São-Miguelian is a fully developed dialect, the standard language has more difficulty in establishing itself... Consequently, very cultured people speak a Luso-São-Miguelian, which is almost São-Miguelian, at least as far as the pronunciation is concerned. (1940: 471)

In contrast, speaker L, with his clear movement toward a vocalic system that is far more Standard than "São-Miguelian," assigned to the box corresponding to "High Portuguese Contact-Participation but Low Micaelense Maintenance."

\begin{tabular}{|c|c|c|c|}
\hline & & \multicolumn{2}{|c|}{ Maintenance of Micaelense Language } \\
\hline & & High & Low \\
\hline & High & $\begin{array}{c}\text { Integrated / Bicultural } \\
\text { (Accommodated } \\
\text { Micaelense) }\end{array}$ & $\begin{array}{c}\text { Assimilated } \\
\text { (Standard-like } \\
\text { Portuguese) }\end{array}$ \\
$\begin{array}{c}\text { Participation } \\
\text { with Larger } \\
\begin{array}{c}\text { Lusophone } \\
\text { Community }\end{array}\end{array}$ & Low & $\begin{array}{c}\text { Traditionalist / } \\
\text { Segregationist } \\
\text { (Stereotyped Micaelense) }\end{array}$ & $\begin{array}{c}\text { Marginalized } \\
\text { (No Portuguese Spoken) }\end{array}$ \\
\hline
\end{tabular}

Figure 11: Matrix of Micaelense Language Maintenance vs. Contact-Participation with the Larger Lusophone Community

What remains to be further explored with respect to these potential connections between identity and speech behavior among the Micaelense is the possibility for developing an even richer three-dimensional matrix, one that might array American-, Portuguese- and Micaelense-Identity along the $x$-, $y$-, and $z$-axes. Such a study would best be conducted in the larger Lusophone immigrant communities of North America, with an eye toward better assessing the dynamics of how Portuguese speakers (broadly defined) relate to both the socially dominant Anglophone culture and to the (arguably) socially 
dominated sub-cultures of various geographically-defined speech areas, such as São Miguel. Further intellectual fruit might be harvested by carrying this model directly into São Miguel and assessing the linguistic attitudes and behaviors of a burgeoning population of non-Lusophone immigrants to the island: for example, as the children of recently-arrived Eastern Europeans situate themselves into the local community, what sorts of linguistic behaviors do they adopt? What linguistic norms might they observe? These and related questions should provide ample opportunities for future sociolinguistic inquiry into one of the most isolated - and linguistically diverse - corners of the Lusophone universe.

\section{Acknowledgements}

I wish to thank The University of Texas Arlington's Research Enhancement Program for supporting the fieldwork that gave rise to the current work. I am likewise grateful for comments from two anonymous reviewers of the text. Finally, my heartfelt thanks got to the Azorean immigrants who allowed me to interrupt their lives what might have appeared to be such silly questions; I'm sure many of them wondered why such an ptherwise intelligent looking fellow didn't know how to identify a carrot, or a house, or a pair of scissors. Without their help, we would know far less about the extent to which their unique brand of Portuguese survives outside its insular homeland.

\section{References}

Bell, R. T. (1983) Sociolinguistics. London: B. T. Batsford.

Berry, J. (2003) Conceptual approaches to acculturation. In Acculturation: advances in theory, measurement, and applied research, (K. M. Chun, P. B. Organista \& Gerardo Marín, editors), pp. 17-37, Washington, DC: American Psychological Association.

Blayer, I. M. F. (1992) Aspects of the vocalic system in the speech of the Azores islands. Doctoral dissertation, University of Toronto.

Cintra, L. L. (1983) Estudos de Dialectologia Portuguesa. Lisbon: Sá da Costa Editora.

Crystal, D. (1997) The Cambridge encyclopedia of language, second edition. Cambridge: Cambridge University Press.

Dias, F. L. F. (2000) Origens do Português Micaelense: Abordagem diacrónica do sistema vocálico. A Voz Popular: Estudos de Etnolinguística. Cascais: Patrimonia, pp. 53-80.

Gonçalves Vianna, A. R. (1887-89) Notas sobre a fonética dialectal de Ponta-Delgada, Revista Lusitana I, 223-26.

Labov, W. (1972) Sociolinguistic patterns. Philadelphia: U of Pennsylvania Press. 
Ladefoged, P. \& I. Maddieson (1996) The sounds of the world's languages. Oxford: Blackwell.

Leite de Vasconcellos, J. (1890-92) Dialectos Acoreanos (contribuições para o estudo da Dialectologia Portuguesa), Revista Lusitana II, 289-307.

Marsella, A. J., \& V. Kameoka. (1989) Ethnocultural issues in the assessment of psychopathology. In Measuring mental illness: Psychiatric assessment for clinicians (S. Wetzler, editor), pp. 231-256. Washington: American Psychiatric Press.

Martinet, A. (1952) Function, structure, and sound change. Reprinted in Readings in historical phonology: Chapters in the theory of sound change (P. Baldi \& R. N. Werth, editors), pp. 121-159. University Park: Pennsylvania State University Press.

Martins, M. R. D. (1988) Ouvir falar, $3^{\mathrm{a}}$ edição. Lisboa: Caminho.

Mateus, M. H. M. (1982) Aspectos da fonologia portuguesa. Lisboa: Centro de Estudos Filológicos.

Milroy, L. (1987) Language and social networks, $2^{\text {nd }}$ edition. Oxford: Basil Blackwell.

Rogers, F. M. (1940) The production of the Madeira and Azores dialects as compared with standard Portuguese. Doctoral Dissertation, Harvard University.

. (1948). Insular Portuguese pronunciation: Porto Santo and eastern Azores. Hispanic Review XVI (1), 1-32.

Rolão Bernardo, M. C. and H. M. Montenegro (2003) O falar micaelense: fonética e léxico. Mirandela: João Azevedo Editor.

Silva, D. J. (1986) New Perspectives on the Portuguese Vowel Shift. Undergraduate Honors Thesis, Harvard University.

_ (1997) The Variable Deletion of Unstressed Vowels in Azorean Portuguese. Language Variation and Change 9 (3), 1-15.

. (1998) Vowel Elision in São Miguel Portuguese. Hispania 81, 166-178.

(2005) Vowel shifting as a marker of social identity in the Portuguese dialect of Nordeste, São Miguel (Azores). Luso-Brazilian Review 42 (1), 1-27.

\section{David J. Silva}

The University of Texas at Arlington

Office of the Provost, The University of Texas at Arlington

UTA Box 19118 - Davis Hall 300

701 South Nedderman Drive

Arlington, TX 76019-0118 USA

djsilva@uta.edu 


\section{Appendix}

This table lists the lexical items corresponding to the images presented to participants, presented below in alphabetical order. Items with nasalized tonic vowels have been omitted.

\begin{tabular}{|c|}
\hline 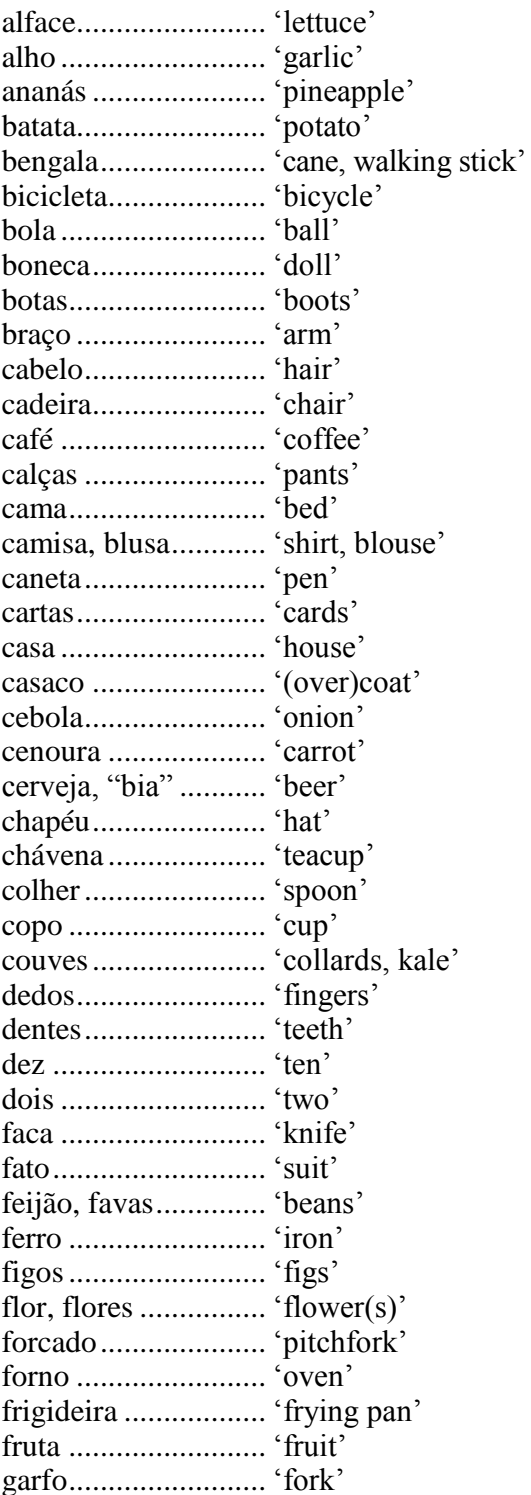 \\
\hline
\end{tabular}

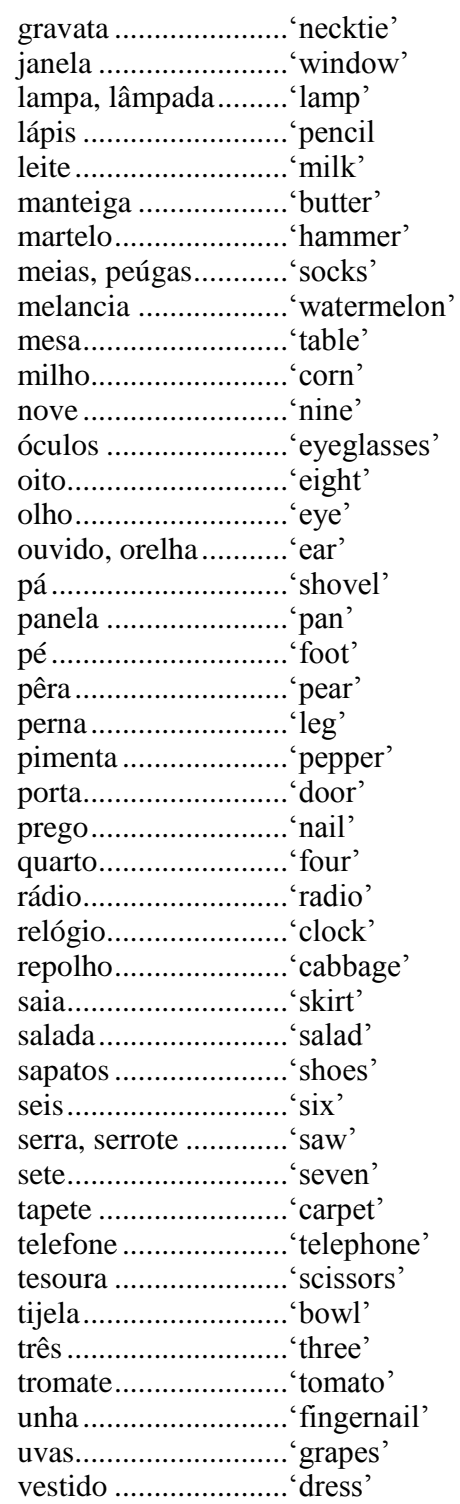

